\title{
Mössbauer Studies of Nickel-Iron Hydrotalcites
}

\author{
U. Pegelow ${ }^{\mathrm{a}}$, M. Winterer ${ }^{\mathrm{a} *}$, B. D. Mosel ${ }^{\mathrm{a}}$, M. Schmalz ${ }^{\mathrm{b}}$, and R. Schöllhorn ${ }^{\mathrm{b}}$ \\ a Institut für Physikalische Chemie der Universität Münster, Schloßplatz 4/7, D-48149 Münster \\ b Institut für Anorganische und Analytische Chemie der Technischen Universität Berlin
}

Z. Naturforsch. 49a, 1200-1206 (1994); received September 26, 1994

\section{Dedicated to Professor Werner Müller-Warmuth on the occasion of his 65th birthday}

Hydrotalcite-like $\mathrm{Fe}-\mathrm{Ni}$-hydroxides $\left[\mathrm{Ni}_{2 / 3}^{\mathrm{II}} \mathrm{Fe}_{1 / 3}^{\mathrm{III}}(\mathrm{OH})_{2}\right]\left(\mathrm{CO}_{3}\right)_{1 / 6}\left(\mathrm{H}_{2} \mathrm{O}\right)_{y}, \quad\left[\mathrm{Ni}_{3 / 4}^{\mathrm{II}} \mathrm{Fe}_{1 / 4}^{\mathrm{III}}(\mathrm{OH})_{2}\right]-$ $\left(\mathrm{CO}_{3}\right)_{1 / 8}\left(\mathrm{H}_{2} \mathrm{O}\right)_{y}$ and $\left[\mathrm{Ni}_{3 / 4}^{\mathrm{II} / \mathrm{III}} \mathrm{Fe}_{1 / 4}^{\mathrm{III}}(\mathrm{OH})_{2}\right]\left(\mathrm{CO}_{3}\right)_{0,14}\left(\mathrm{H}_{2} \mathrm{O}\right)_{y}$ as well as the ternary oxide $\mathrm{NaNi}_{2 / 3} \mathrm{Fe}_{1 / 3} \mathrm{O}_{2}$ have been studied by ${ }^{57} \mathrm{Fe}-\mathrm{Mössbauer}$ spectroscopy. All samples contain $\mathrm{Fe}^{3+}$ in a high spin state. The quadrupole interaction is smaller if a magnetic splitting is present, which may indicate a non-parallel arrangement of the principal axis of the EFG and the hyperfine field. The temperature dependence of the spectra has been understood in terms of collective cluster excitations. In this model the magnetic energy of a single domain depends on the direction of the total magnetic moment and on magnetic interaction with the neighbourhood. The spectral lineshape could be fitted assuming uniaxial relaxation.

Key words: Mössbauer spectroscopy, Nickel-iron hydrotalcite, $\mathrm{Fe}(\mathrm{III})$ high spin, Collective cluster excitations.

\section{Introduction}

Hydrotalcite-like compounds are analogous to the naturally occuring mineral $\left[\mathrm{Mg}_{3 / 4} \mathrm{Al}_{1 / 4}(\mathrm{OH})_{2}\right]$ $\left(\mathrm{CO}_{3}\right)_{1 / 8}\left(\mathrm{H}_{2} \mathrm{O}\right)_{y}$ and widely used in catalysis, e.g. with aldol condensation [1]. Their ability to act as anion exchangers makes them valuable for studying topotactic solid state reactions $[2,3]$. Derivatives containing transition metal cations are of special interest because they are expected to undergo changes in the oxidation state without alteration of their matrix [4]. ${ }^{57} \mathrm{Fe}$ Mössbauer spectroscopy is a powerful tool to determine the oxidation state of iron as well as to investigate the magnetic properties of the system. We have examined in particular the compounds $\left[\mathrm{Ni}_{2 / 3} \mathrm{Fe}_{1 / 3}(\mathrm{OH})_{2}\right]\left(\mathrm{CO}_{3}\right)_{1 / 6}\left(\mathrm{H}_{2} \mathrm{O}\right)_{y},\left[\mathrm{Ni}_{3 / 4} \mathrm{Fe}_{1 / 4}(\mathrm{OH})_{2}\right]-$ $\left(\mathrm{CO}_{3}\right)_{x}\left(\mathrm{H}_{2} \mathrm{O}\right)_{y}$ and the ternary oxide $\mathrm{NaNi}_{2 / 3} \mathrm{Fe}_{1 / 3} \mathrm{O}_{2}$; the latter phase is used as starting material in the preparation of the first compound. Two samples of $\left[\mathrm{Ni}_{3 / 4} \mathrm{Fe}_{1 / 4}(\mathrm{OH})_{2}\right]\left(\mathrm{CO}_{3}\right)_{x}\left(\mathrm{H}_{2} \mathrm{O}\right)_{y}$ were investigated, one contains divalent nickel only $(x=1 / 8)$, and the other one in addition some remaining $\mathrm{Ni}^{3+}(x=0.14)$.

\footnotetext{
* Present address: FB Materialwissenschaft, TH Darmstadt, Germany.
}

Reprint requests to Dr. B. Mosel.

\section{Experimental}

\subsection{Sample Preparation}

The ternary oxide was prepared by heating a well ground stoichiometric mixture of the corresponding transition metal oxides $\left(\mathrm{NiO}\right.$ and $\alpha-\mathrm{Fe}_{2} \mathrm{O}_{3}$ ) with a $100 \%$ excess of $\mathrm{Na}_{2} \mathrm{O}_{2}$ for one day at $1000 \mathrm{~K}$ in a $\mathrm{Pt}$ crucible in a dry oxygen atmosphere [4]:

$$
\begin{aligned}
& 2 \mathrm{NiO}+\frac{1}{2} \mathrm{Fe}_{2} \mathrm{O}_{3}+\mathrm{Na}_{2} \mathrm{O}_{2}+\frac{1}{2} \mathrm{Na}_{2} \mathrm{O} \\
& \rightarrow 3 \mathrm{NaNi}_{2 / 3} \mathrm{Fe}_{1 / 3} \mathrm{O}_{2} .
\end{aligned}
$$

A reduction in volume was observed when cooling the dark grey and brittle crystal powder. Excess $\mathrm{Na}_{2} \mathrm{O}_{2}$ was removed by washing with ethanol. A Guinier film was taken to characterize the ternary oxide. The monophasic product forms a layered $\mathrm{CdI}_{2}$ type structure with hexagonal lattice parameters (Table 1). The structure consists of parallel aligned $\mathrm{Na}-$ and $\mathrm{Ni} / \mathrm{Fe}$-layers which are separated by sheets of oxygen. $\mathrm{Na}, \mathrm{Ni}$ and $\mathrm{Fe}$ are coordinated by oxygen in the shape of a trigonally distorted octahedron. X-ray diffraction gives no evidence of any ordering of iron and nickel within their layer, and hence a random distribution may be concluded [5]. The ternary oxide $\mathrm{NaNi}_{3 / 4} \mathrm{Fe}_{1 / 4} \mathrm{O}_{2}$ was obtained under similar conditions. 
Table 1. Hexagonal lattice parameters of the compounds under investigation; $d=$ interlayer distance.

\begin{tabular}{lccc}
\hline & $a / \mathrm{nm}$ & $c / \mathrm{nm}$ & $d / \mathrm{nm}$ \\
\hline $\mathrm{NaNi}_{2 / 3} \mathrm{Fe}_{1 / 3} \mathrm{O}_{2}$ & 0.298 & 1.588 & 0.529 \\
{$\left[\mathrm{Ni}_{2 / 3}^{\mathrm{II}} \mathrm{Fe}_{1 / 3}^{\mathrm{III}}(\mathrm{OH})_{2}\right]\left(\mathrm{CO}_{3}\right)_{1 / 6}\left(\mathrm{H}_{2} \mathrm{O}\right)_{y}$} & 0.307 & 2.316 & 0.772 \\
{$\left[\mathrm{Ni}_{3 / 4}^{\mathrm{II}} \mathrm{Fe}_{1 / 4}^{\mathrm{II}}(\mathrm{OH})_{2}\right]\left(\mathrm{CO}_{3}\right)_{1 / 8}\left(\mathrm{H}_{2} \mathrm{O}\right)_{y}$} & 0.310 & 2.347 & 0.782 \\
{$\left[\mathrm{Ni}_{3 / 4}^{\mathrm{II} / \mathrm{III}} \mathrm{Fe}_{1 / 4}^{\mathrm{III}}(\mathrm{OH})_{2}\right]\left(\mathrm{CO}_{3}\right)_{0.14}\left(\mathrm{H}_{2} \mathrm{O}\right)_{y}$} & 0.309 & 2.318 & 0.773 \\
\hline
\end{tabular}

The hydrotalcite-like compounds $\left[\mathrm{Ni}_{2 / 3}^{\mathrm{II}} \mathrm{Fe}_{1 / 3}^{\mathrm{III}}(\mathrm{OH})_{2}\right]-$ $\left(\mathrm{CO}_{3}\right)_{1 / 6}\left(\mathrm{H}_{2} \mathrm{O}\right)_{y}$, and $\left[\mathrm{Ni}_{3 / 4}^{\mathrm{II}} \mathrm{Fe}_{1 / 4}^{\mathrm{III}}(\mathrm{OH})_{2}\right]\left(\mathrm{CO}_{3}\right)_{1 / 8}\left(\mathrm{H}_{2} \mathrm{O}\right)_{y}$, are prepared from the corresponding ternary oxides in a topotactical redox protolysis reaction. A 1 molar solution of $\mathrm{Na}_{2} \mathrm{SO}_{3}$ is added in small portions to a suspension of $1 \mathrm{~g}$ ternary oxide in $100 \mathrm{ml}$ of water until the color has completely changed to brown; subsequently $\mathrm{Na}_{2} \mathrm{CO}_{3}$ was added:

$$
\begin{aligned}
& \mathrm{NaNi}_{2 / 3} \mathrm{Fe}_{1 / 3} \mathrm{O}_{2}+\frac{1}{3} \mathrm{SO}_{3}^{2-}+\frac{5}{3} \mathrm{H}_{2} \mathrm{O} \\
&+\frac{1}{6} \mathrm{CO}_{3}^{2-}+y \mathrm{H}_{2} \mathrm{O} \\
& \rightarrow\left[\mathrm{Ni}_{2 / 3} \mathrm{Fe}_{1 / 3}(\mathrm{OH})_{2}\right]\left(\mathrm{CO}_{3}\right)_{1 / 6}\left(\mathrm{H}_{2} \mathrm{O}\right)_{y} \\
&+\frac{1}{3} \mathrm{SO}_{4}^{2-}+\mathrm{Na}^{+}+\frac{4}{3} \mathrm{OH}^{-} .
\end{aligned}
$$

Mechanistically, this reaction is a reduction of the $\left[\mathrm{Ni}_{1-x} \mathrm{Fe}_{x} \mathrm{O}_{2}\right]^{-}$layer accompanied by a complete protonation of oxygen, a deintercalation of sodium and an intercalation of $\mathrm{CO}_{3}^{2-}$ and water molecules. The structure consists of positively charged metal-hydroxide layers intercalated by anions and water. Chemical analysis yields $y=1.3$. The guest species are mobile and exchangeable by other anions.

The brown colour of both phases $\left[\mathrm{Ni}_{2 / 3}^{\mathrm{II}} \mathrm{Fe}_{1 / 3}^{\mathrm{III}}(\mathrm{OH})_{2}\right]$ $\left(\mathrm{CO}_{3}\right)_{1 / 6}\left(\mathrm{H}_{2} \mathrm{O}\right)_{y}$ and $\left[\mathrm{Ni}_{3 / 4}^{\mathrm{II}} \mathrm{Fe}_{1 / 4}^{\mathrm{III}}(\mathrm{OH})_{2}\right]\left(\mathrm{CO}_{3}\right)_{1 / 8}\left(\mathrm{H}_{2} \mathrm{O}\right)_{y}$ indicates the presence of divalent nickel and trivalent iron ions. If the weaker reducing agent urea is used instead of $\mathrm{Na}_{2} \mathrm{SO}_{3}$ a different product $\left[\mathrm{Ni}_{3 / 4}^{\mathrm{II} / \mathrm{III}} \mathrm{Fe}_{1 / 4}^{\mathrm{III}}(\mathrm{OH})_{2}\right]\left(\mathrm{CO}_{3}\right)_{x}\left(\mathrm{H}_{2} \mathrm{O}\right)_{y}$ is formed which exhibits a black colour due to the presence of some remaining $\mathrm{Ni}^{3+}$. Chemical analysis gives a content of about $4 \% \mathrm{Ni}^{3+}$ corresponding to $x=0.14$.

Table 1 summarizes the lattice parameters of the compounds investigated. Due to the stacking sequence, the hexagonal parameter $c$ equals three times the interlayer distance $d$.

Electron microscopic studies reveal that the crystallites of the starting materials have a diameter of $4 \mu \mathrm{m}$ in $a$-b-direction and a thickness of 1 to $2 \mu \mathrm{m}$ in $c$-direction [4]. However, from the width of the X-ray diffraction 001-peak of the reduced phase one has to conclude that the thickness is only about 8 to $16 \mathrm{~nm}$.
This can be understood in terms of a breaking up the larger crystallites into a mosaic like structure [5].

\subsection{Mössbauer Measurements}

The ${ }^{57} \mathrm{Fe}$ Mössbauer spectra were collected using a constant acceleration method with the ${ }^{57} \mathrm{Co} / \mathrm{Rh}$ source held at room temperature. The temperature of the absorber was adjusted between $4.2 \mathrm{~K}$ and $300 \mathrm{~K}$. An acrylic glass container was used to achieve an absorber thickness of the powdered samples between 0.1 and $0.2 \mathrm{mg}{ }^{57} \mathrm{Fe} / \mathrm{cm}^{2}$. The velocity scale was calibrated with the spectrum of an $\alpha$-Fe foil; all isomer shifts are reported relative to $\alpha-\mathrm{Fe}$ at $300 \mathrm{~K}$.

\section{Results}

$\mathrm{NaNi}_{2 / 3} \mathrm{Fe}_{1 / 3} \mathrm{O}_{2}$ was measured at temperatures between $4.2 \mathrm{~K}$ and $30 \mathrm{~K}$ (Figure 1). At $30 \mathrm{~K}$ the spectrum consists of a single doublet with a linewidth $\left(\Gamma=0.45(1) \mathrm{mm} \mathrm{s}^{-1}\right)$ that is broadened compared to the natural linewidth of ${ }^{57} \mathrm{Fe}\left(\Gamma \approx 0.2 \mathrm{~mm} \mathrm{~s}^{-1}\right)$. When lowering the temperature an onset of a magnetic splitting is observed. However the lines are asymmetrically broadened and do not show the $3: 2: 1$ intensity ratio typical of iron even at $4.2 \mathrm{~K}$. The spectra were fitted using the model of uniaxial relaxation [6] keeping the magnetic hyperfine field constant at the value obtained at $4.2 \mathrm{~K}$ in order to get reasonable fits. Fitting parameters are presented in Table 2.

Spectra of the hydrotalcite-like compounds (Figs. 2 to 4) show the same characteristics as the ternary oxide, a doublet at temperatures above $15 \mathrm{~K}$ and a gradually evolving magnetic splitting when the temperature is lowered. $\left[\mathrm{Ni}_{3 / 4}^{\mathrm{II} / \mathrm{III}} \mathrm{Fe}_{1 / 4}^{\mathrm{III}}(\mathrm{OH})_{2}\right]\left(\mathrm{CO}_{3}\right)_{0.14^{-}}$ $\left(\mathrm{H}_{2} \mathrm{O}\right)_{y}$ shows a second contribution $(\approx 30 \%)$ which is fitted using a static sextett. Tables 3 to 5 list the obtained parameters.

\section{Discussion}

From the isomer shift $\delta$ and the quadrupole splitting $\Delta E_{\mathrm{Q}}$ of $\mathrm{NaNi}_{2 / 3} \mathrm{Fe}_{1 / 3} \mathrm{O}_{2}$ at $30 \mathrm{~K}$ and those of the hydrotalcite-like compounds (Tables $2-5$ ) it is concluded that iron occurs as high-spin $\mathrm{Fe}^{3+}$ in all samples. The increased linewidth at all temperatures is probably due to a random occupation of the transi- 

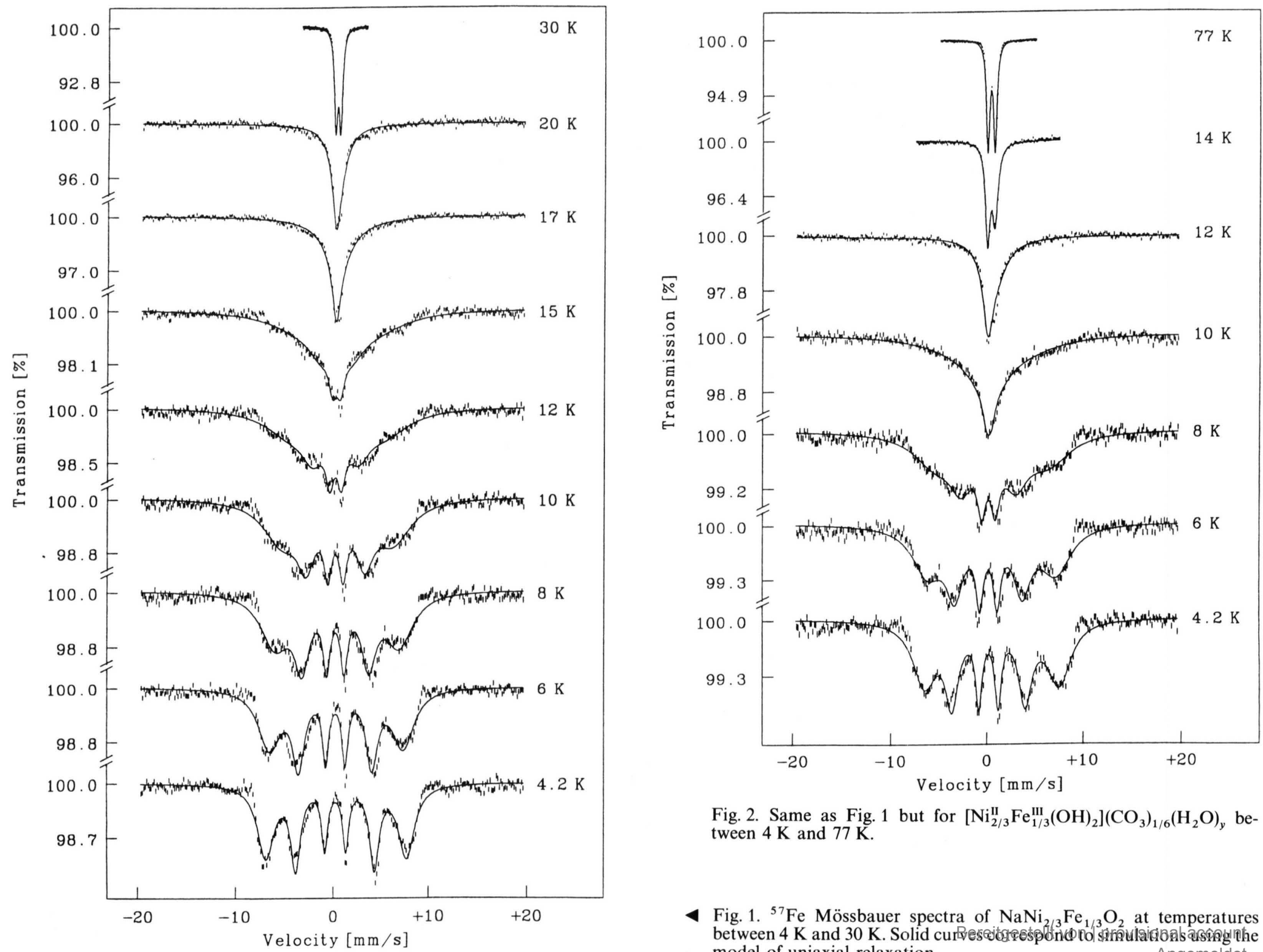

Fig. 2. Same as Fig. 1 but for $\left[\mathrm{Ni}_{2 / 3}^{\mathrm{II}} \mathrm{Fe}_{1 / 3}^{\mathrm{IIII}}(\mathrm{OH})_{2}\right]\left(\mathrm{CO}_{3}\right)_{1 / 6}\left(\mathrm{H}_{2} \mathrm{O}\right)_{y}$ between $4 \mathrm{~K}$ and $77 \mathrm{~K}$.

Fig. 1. ${ }^{57} \mathrm{Fe}$ Mössbauer spectra of $\mathrm{NaNi}_{3} \mathrm{Fe}_{13} \mathrm{O}_{2}$ at temperatures between $4 \mathrm{~K}$ and $30 \mathrm{~K}$. Solid cur model of uniaxial relaxation. Angemeldet 


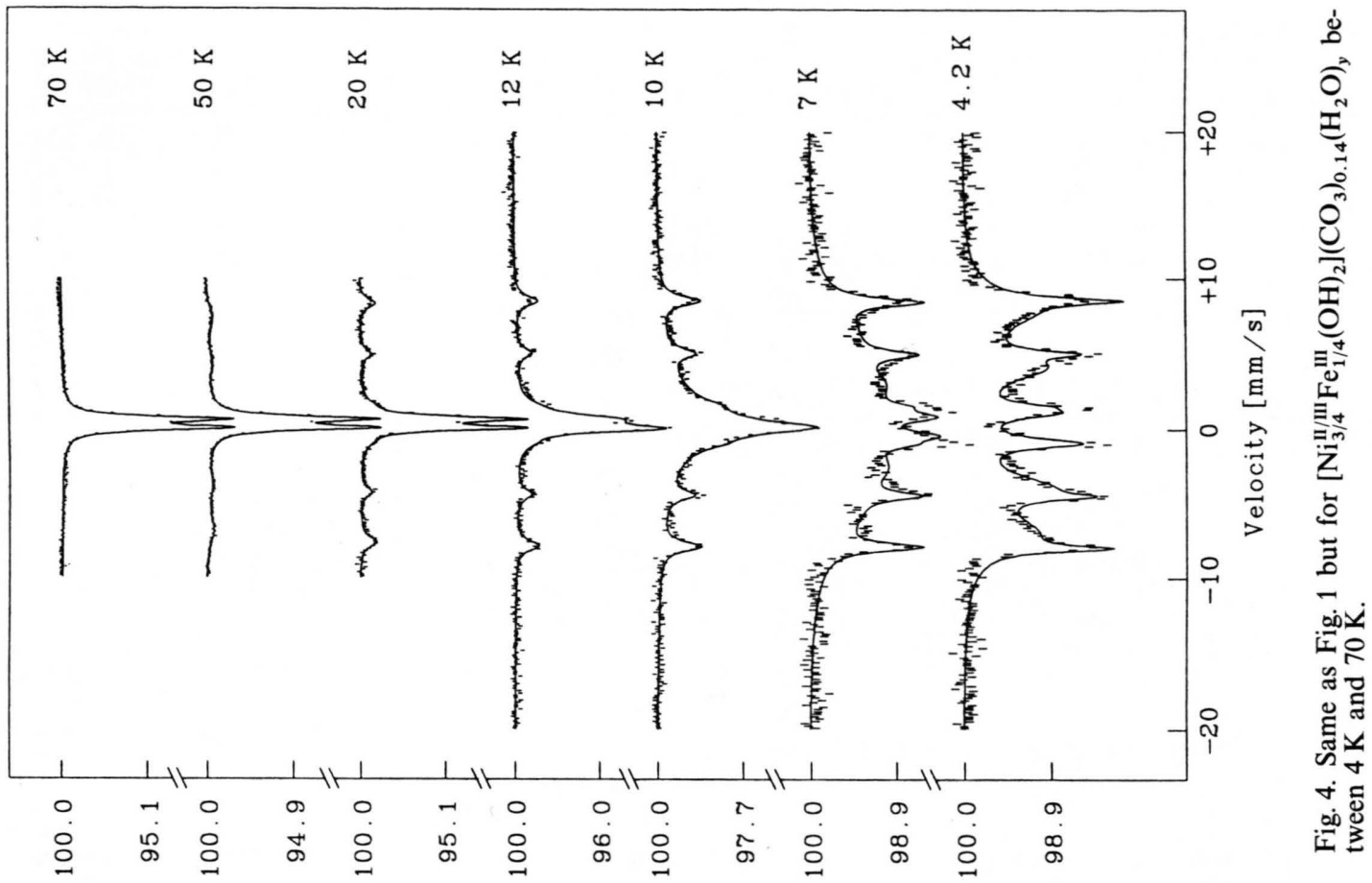

[\%] uoṭsṭusuex

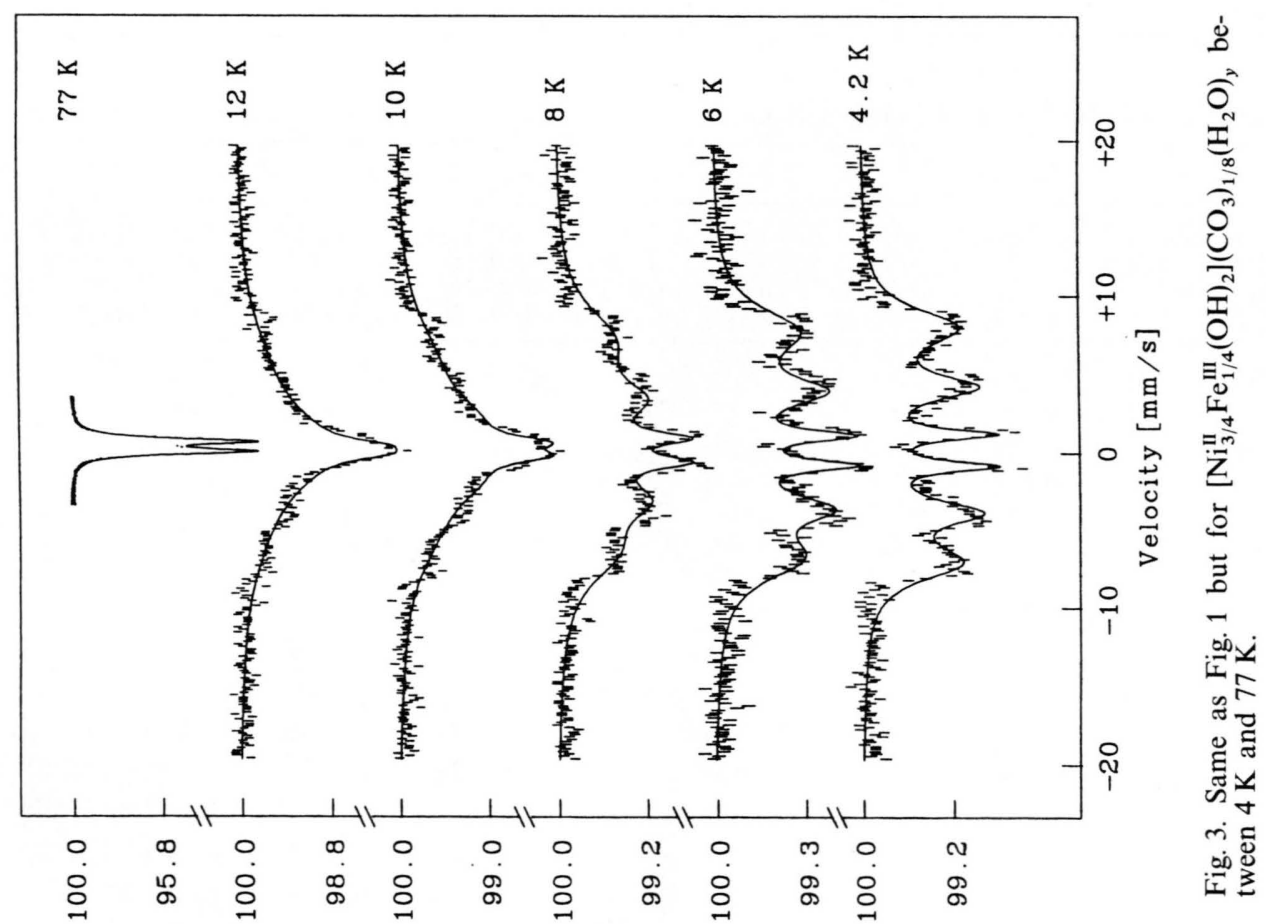

[\%] uoṭsṭusuex 
Table 2. Fitting parameters of $\mathrm{NaNi}_{2 / 3} \mathrm{Fe}_{1 / 3} \mathrm{O}_{2}$.

\begin{tabular}{llllllllll}
\hline$T / \mathrm{K}$ & 4.2 & 6 & 8 & 10 & 12 & 15 & 17 & 20 & 30 \\
\hline$\delta / \mathrm{mm} \mathrm{s}^{-1}$ & $0.46(3)$ & $0.45(4)$ & $0.46(7)$ & $0.46(5)$ & $0.45(8)$ & $0.56(1)$ & $0.52(3)$ & $0.47(3)$ & $0.452(3)$ \\
$\Gamma / \mathrm{mm} \mathrm{s}^{-1}$ & $0.74(8)$ & $0.75(8)$ & $0.8(1)$ & $0.9(1)$ & $0.9(2)$ & $0.9(2)$ & $0.8(1)$ & $0.8(2)$ & $0.45(1)$ \\
$\Delta E_{\mathrm{Q}} / \mathrm{mm} \mathrm{s}^{-1}$ & $0.17(6)$ & $0.17(8)$ & $0.2(1)$ & 0.2 & 0.2 & 0.2 & 0.2 & 0.2 & $0.519(5)$ \\
$\left|B_{\mathrm{HF}}\right| / \mathrm{T}$ & $56(5)$ & 56 & 56 & 56 & 56 & 56 & 56 & 56 & - \\
$f / \mathrm{GHz}$ & $3(1)$ & $2.4(2)$ & $2.2(2)$ & $2.0(2)$ & $1.6(2)$ & $1.5(2)$ & $3.1(4)$ & $8(3)$ & - \\
$\xi$ & $0.79(6)$ & $0.73(1)$ & $0.66(1)$ & $0.57(1)$ & $0.43(2)$ & $0.29(2)$ & 0 & 0 & - \\
\hline
\end{tabular}

Table 3. Fitting parameters of $\left[\mathrm{Ni}_{2 / 3}^{\mathrm{II}} \mathrm{Fe}_{1 / 3}^{\mathrm{III}}(\mathrm{OH})_{2}\right]\left(\mathrm{CO}_{3}\right)_{1 / 6}\left(\mathrm{H}_{2} \mathrm{O}\right)_{y}$.

\begin{tabular}{llllllllll}
\hline$T / \mathrm{K}$ & 4.2 & 6 & 8 & 10 & 12 & 14 & 20 & 77 & 298 \\
\hline$\delta / \mathrm{mm} \mathrm{s}^{-1}$ & $0.47(5)$ & $0.44(8)$ & $0.45(8)$ & $0.45(8)$ & $0.56(7)$ & $0.471(7)$ & $0.474(2)$ & $0.464(2)$ & $0.361(3)$ \\
$\Gamma / \mathrm{mm} \mathrm{s}^{-1}$ & $0.75(9)$ & $0.8(1)$ & $0.9(2)$ & 0.9 & $0.9(2)$ & $0.54(2)$ & $0.455(4)$ & $0.424(5)$ & $0.40(1)$ \\
$\Delta E_{\mathrm{Q}} / \mathrm{mm} \mathrm{s}^{-1}$ & $0.36(9)$ & $0.3(1)$ & 0.3 & $0.3(1)$ & $0.7(2)$ & $0.76(1)$ & $0.76(1)$ & $0.75(1)$ & $0.76(1)$ \\
$\mid B_{\mathrm{HF}} / \mathrm{T}$ & $54(4)$ & 54 & 54 & 54 & 54 & 54 & - & - & - \\
$f / \mathrm{GHz}$ & $1.8(7)$ & $1.5(2)$ & $1.3(2)$ & $1.3(2)$ & $5(1)$ & $60(10)$ & - & - & - \\
$\xi$ & $0.74(4)$ & $0.66(1)$ & $0.51(2)$ & $0.18(4)$ & $0.0(1)$ & 0 & - & - & - \\
\hline
\end{tabular}

Table 4. Fitting parameters of $\left[\mathrm{Ni}_{3 / 4}^{\mathrm{II}} \mathrm{Fe}_{1 / 4}^{\mathrm{III}}(\mathrm{OH})_{2}\right]\left(\mathrm{CO}_{3}\right)_{1 / 8}\left(\mathrm{H}_{2} \mathrm{O}\right)_{y}$.

\begin{tabular}{llllllll}
\hline$T / \mathrm{K}$ & 4.2 & 6 & 8 & 10 & 12 & 15 & 77 \\
\hline$\delta / \mathrm{mm} \mathrm{s}^{-1}$ & $0.45(6)$ & $0.4(1)$ & $0.44(8)$ & $0.49(8)$ & $0.43(8)$ & $0.47(2)$ & $0.460(3)$ \\
$\Gamma / \mathrm{mm} \mathrm{s}^{-1}$ & $0.7(1)$ & $0.8(1)$ & $0.8(2)$ & $0.8(2)$ & $0.8(4)$ & $0.72(7)$ & $0.47(1)$ \\
$\Delta E_{\mathrm{Q}} / \mathrm{mm} \mathrm{s}^{-1}$ & $0.3(1)$ & $0.3(2)$ & 0.3 & 0.3 & 0.3 & $0.73(4)$ & $0.64(1)$ \\
$\left|B_{\mathrm{HF}}\right| \mathrm{T}$ & $53(2)$ & 53 & 53 & 53 & 53 & 53 & - \\
$f / \mathrm{GHz}$ & $1.0(3)$ & $1.1(2)$ & $1.0(1)$ & $1.1(1)$ & $1.1(2)$ & $24(6)$ & - \\
$\xi$ & $0.76(3)$ & $0.69(2)$ & $0.55(2)$ & $0.32(3)$ & $0.2(1)$ & 0 & - \\
\hline
\end{tabular}

Table 5. Fitting parameters of $\left[\mathrm{Ni}_{3 / 4}^{\mathrm{II} / \mathrm{III}} \mathrm{Fe}_{1 / 4}^{\mathrm{III}}(\mathrm{OH})_{2}\right]\left(\mathrm{CO}_{3}\right)_{0.14}\left(\mathrm{H}_{2} \mathrm{O}\right)_{y}$.

\begin{tabular}{|c|c|c|c|c|c|c|c|c|c|c|}
\hline$T / \mathrm{K}$ & 4.2 & 7 & 10 & 12 & 15 & 20 & 40 & 50 & 70 & 300 \\
\hline Rel. Abs. ${ }_{1}$ & 0.14 (2) & 0.15 (1) & $0.14(2)$ & 0.14 (1) & $0.168(5)$ & $0.177(6)$ & $0.182(4)$ & $0.181(3)$ & $0.176(3)$ & $0.142(7)$ \\
\hline$\delta_{1} / \mathrm{mm} \mathrm{s}^{-1}$ & $0.46(7)$ & $0.45(7)$ & $0.5(1)$ & $0.48(2)$ & 0.47 (1) & 0.47 (1) & $0.46(1)$ & $0.456(4)$ & 0.449 (4) & 0.34 (1) \\
\hline$\Gamma_{1} / \mathrm{mm} \mathrm{s}^{-1}$ & 0.7 (1) & 0.7 (1) & 0.7 (1) & $0.51(5)$ & $0.43(1)$ & $0.43(2)$ & $0.43(1)$ & $0.43(1)$ & 0.44 (1) & $0.47(3)$ \\
\hline$\Delta E_{\mathrm{Q} 1} / \mathrm{mm} \mathrm{s}^{-1}$ & $0.3(1)$ & $0.2(1)$ & $0.5(3)$ & $0.63(4)$ & 0.60 (1) & $0.60(1)$ & 0.59 (1) & 0.59 (1) & 0.59 (1) & $0.58(2)$ \\
\hline$\left|B_{\mathrm{HF}_{1}}\right| / \mathrm{T}$ & $50.0(2)$ & $50.5(2)$ & $50.6(3)$ & $50.4(5)$ & $49.8(2)$ & - & - & - & - & - \\
\hline$f_{1} / \mathrm{GHz}$ & 0.9 (2) & $1.0(2)$ & $2.2(4)$ & $29(8)$ & $100(20)$ & - & - & - & - & - \\
\hline$\xi_{1}$ & $0.76(2)$ & 0.49 (3) & 0 & 0 & 0 & - & - & - & - & - \\
\hline Rel. Abs. ${ }_{2}$ & $0.061(8)$ & $0.048(5)$ & $0.044(5)$ & $0.046(8)$ & 0.041 (4) & $0.038(7)$ & $0.022(4)$ & $0.017(3)$ & - & - \\
\hline$\delta_{2} / \mathrm{mm} \mathrm{s}^{-1}$ & $0.43(3)$ & $0.42(3)$ & $0.45(4)$ & $0.44(4)$ & $0.43(3)$ & $0.45(7)$ & $0.4(1)$ & $0.3(1)$ & - & - \\
\hline$\Gamma_{2} / \mathrm{mm} \mathrm{s}^{-1}$ & $0.5(1)$ & $0.6(1)$ & 0.7 (1) & $0.8(2)$ & 0.7 (1) & $0.8(3)$ & $1.5(5)$ & $2.0(6)$ & - & - \\
\hline$\left|B_{\mathrm{HF}_{2}}\right| / \mathrm{T}$ & $51.1(2)$ & $50.5(2)$ & $50.6(3)$ & $50.4(5)$ & $49.8(2)$ & $49.2(5)$ & $45.8(7)$ & 44 (1) & - & - \\
\hline
\end{tabular}

tion metal sites with $\mathrm{Fe}$ and $\mathrm{Ni}$ leading to a distribution of $\delta$ and $\Delta E_{\mathrm{Q}}$.

The temperature dependence of the lineshape is very similar to that found in a number of microcrystalline compounds like ferrihydrite $\left(\mathrm{Fe}_{5} \mathrm{HO}_{8} \cdot 4 \mathrm{H}_{2} \mathrm{O}\right)$ [7] or goethite $(\alpha-\mathrm{FeOOH})$ [8]. In these cases the observations have been explained by magnetically interacting single domain particles. Similar results have been obtained in numerous compounds where magnetic clusters are responsible for the observed effects, e.g. soliton bearing one-dimensional solids, metallic alloys, amorphous materials, magnetically ordered substances near $T_{\mathrm{c}}$. See Rancourt [9] for a review. On the other hand, lineshapes similar to those observed in this study can also be explained in terms of a distribution of static hyperfine fields. For reasons stated later 


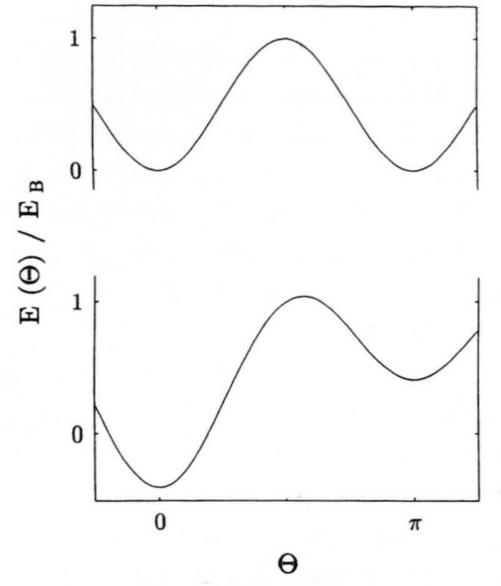

Fig. 5. Anisotropic energy without (top) and with (bottom) interaction between the particles.

on we prefer in this experiment a relaxation model which is described as follows.

In isolated single domain particles the magnetic energy depends on the direction of the total magnetic moment, which is produced by a ferro- or antiferromagnetic interaction. In case of an uniaxial anisotropy the energy may be given by (Fig. 5, top):

$$
E(\Theta)=E_{\mathbf{B}} \sin ^{2} \Theta .
$$

The anisotropy energy $E_{\mathrm{B}}$ is generally assumed to be proportional to the volume $V$ of the microcrystal: $E_{\mathrm{B}}=K V$, with the anisotropy constant $K$. The magnetization can exhibit thermally activated fluctuations between easy directions with $\Theta=0$ and $\Theta=\pi$. This effect is called superparamagnetism [10]. In the high energy barrier approximation $(K V / k T \gg 1)$ the fluctuation frequency is given by [11]

$$
f_{\mathrm{sp}}=\frac{K \gamma_{0}}{M_{\mathrm{S}} \pi^{1 / 2}} \alpha^{1 / 2} \exp [-\alpha],
$$

where $\alpha=K V / k T$. $M_{\mathrm{S}}$ is the magnetic moment per unit volume and $\gamma_{0}$ the gyromagnetic ratio. The transition temperature at which the six-line spectrum collapses into a doublet for a specific particle is called its blocking temperature $T_{\mathrm{B}}$.

A real sample will always show a distribution of particle volumes. Large particles with slow relaxation exhibit a common six line pattern. Small particles produce the doublet spectrum due to fast relaxation. Only an insignificant third portion will have relaxation frequencies which lie in the Mössbauer time window.
The spectrum may thus be described by a superposition of a sextet and a doublet spectrum, whose relative intensities depend on temperature.

Introducing a magnetic interaction between the particles, which can be represented by a reduced effective field $h=M_{\mathrm{S}} V H / 2 E_{\mathrm{B}}=M_{\mathrm{S}} H / 2 K$, we get different probabilities for the magnetization to direct along one of the easy directions (Fig. 5, bottom):

$$
E(\Theta)=E_{\mathbf{B}}\left[\sin ^{2} \Theta-2 h \cos \Theta\right] .
$$

In the uniaxial case we now have two distinct relaxation frequencies not independent because of thermal equilibrium. In the low temperature limit $(\alpha \gg 1)$ these frequencies are given by the approximation [12]

$$
f \pm=\frac{K \gamma_{0}}{M_{\mathrm{S}} \pi^{1 / 2}} \alpha^{1 / 2}\left(1-h^{2}\right)(1 \pm h) \exp \left[-\alpha(1 \pm h)^{2}\right] \text {. }
$$

At sufficiently low temperatures the fluctuation of the magnetization is fixed in either direction during the Mössbauer measurement time and we obtain a single six line spectrum. Likewise, at high temperatures $\left(T>T_{\mathrm{B}}\right)$ the large and alike relaxation frequencies result in a complete collapsing of the magnetic hyperfine splitting, i.e. a doublet spectrum is seen. If a intermediate temperatures the relaxation frequencies lie within the Mössbauer window, transitional-type spectra come up which are most sensitive to unequal relaxation frequencies. This effect is called superferromagnetism [11] if we deal with aggregates of small magnetic particles. Similar formula apply to strongly interacting magnetic clusters with sizes smaller than the particle dimensions.

We have used the model of Dattagupta [6] and van der Woude et al. [13] to calculate the lineshapes. The effect of unequal transition probabilities is expressed by an ordering parameter $\xi$ :

$$
\xi=\frac{f_{+}-f_{-}}{f_{+}+f_{-}} .
$$

$\xi=0$ means that both states have equal occupation probabilities, $\xi=1$ implies that only the state with the lower energy is occupied. It is convenient to define as second parameter the relaxation frequency $f=$ $f_{+}+f_{-}$.

Using the above model we get reasonable fits for $\mathrm{NaNi}_{2 / 3} \mathrm{Fe}_{1 / 3} \mathrm{O}_{2}$ if we take the magnetic hyperfine splitting of $\left|B_{\mathrm{HF}}\right|=55 \mathrm{~T}$ determined at $4.2 \mathrm{~K}$ as a fixed parameter at temperatures from $6 \mathrm{~K}$ to $20 \mathrm{~K}$ (Table 2). The fits reflect correctly the relative intensities of the 
lines and the transition from a sextet to a doublet spectrum. However the calculated lineshapes deviate from the measured ones in that the outer wings are flatter and the inner wings are steeper. This, in conjunction with the increased linewidth $(\Gamma=0.74$ $\left.\mathrm{mm} \mathrm{s}^{-1}\right)$ as compared to the $30 \mathrm{~K}$ spectrum $(\Gamma=0.45$ $\mathrm{mm} \mathrm{s}^{-1}$ ), can be understood in terms of a distribution of particle or cluster volumes and consequently a distribution of relaxation frequencies. In order to reproduce the measured lineshapes the fitting routine will underestimate $\xi$ and overestimate $f$. The blocking temperature of $T_{\mathrm{B}}=22 \mathrm{~K}$ is very small compared with that of typical superferromagnetic samples (e.g. goethite with $T_{\mathrm{B}}=320 \mathrm{~K}$ [8]). This can be due to a very small average particle size. However, recent investigations of the isostructural $\alpha-\mathrm{NaFeO}_{2}$ [14] reveal corresponding lineshapes just below its ordering temperature $T_{\mathrm{N}}=11 \mathrm{~K}$.

It should be stated that one cannot completely rule out a distribution of hyperfine fields as an alternative explanation for the observed effects. E.g., chemical disorder may lead to static spectra with a broad distri- bution of $\left|B_{\mathrm{HF}}\right|$ hence producing lineshapes very similar to those obtained from relaxation. However, since the spectra of $\alpha-\mathrm{NaFeO}_{2}$ near its ordering temperature are well described by a relaxation model that takes into account the magnetic structure and cannot be fitted reasonable by a distribution of hyperfine fields, we prefer to explain the spectra of $\mathrm{NaNi}_{2 / 3} \mathrm{Fe}_{1 / 3} \mathrm{O}_{2}$ as dominated by relaxation effects. These are caused by the presence of cluster excitations.

The results for the three hydrotalcite-like compounds are very similar to those of $\mathrm{NaNi}_{2 / 3} \mathrm{Fe}_{1 / 3} \mathrm{O}_{2}$, where we obtained hyperfine splitting of $53(2) \mathrm{T}$ at $4.2 \mathrm{~K}$ and blocking temperatures of $T_{\mathrm{B}} \approx 14 \mathrm{~K}, T_{\mathrm{B}}$ $\approx 15 \mathrm{~K}$ and $T_{\mathrm{B}} \approx 10 \mathrm{~K}$ respectively. Again the linewidths are noticeably broadened when a magnetic splitting is present, indicating a distribution of relaxation frequencies. Moreover the second spectral contribution of the black hydrotalcite-like sample may be due to a second phase formed by decomposition. Taking into account the $B \approx 51 \mathrm{~T}$ and the high ordering temperature compared to other compounds, this may be assigned to an iron oxyhydroxide.
[1] W. T. Reichle, Solid State Ionics 22, 135 (1986).

[2] R. Schöllhorn, Angew. Chem. 92, 1015 (1980); Angew. Chem. Intern. Ed. Engl. 19, 983 (1980).

[3] R. Schöllhorn, Solid State Ionics 32/33, 23 (1989).

[4] R. Schöllhorn and B. Otto, J. Chem. Soc.: Chem. Commun. 1559 (1987).

[5] B. Otto, PhD thesis, TU Berlin 1988.

[6] S. Dattagupta, Advances in Mössbauer Spectroscopy, page 586. B. V. Thosar, J. K. Srivastava, P. K. Iyengar, and S. L. Bhargava 1983.

[7] L. Chianchi, M. Mancini, G. Spina, and H. Tang, J. Phys.: Condens. Mater. 4, 2073 (1992).

[8] S. Mørup, M. B. Madsen, J. Franck, J. Villadsen, and C. J. W. Koch, J. Magn. Magn. Mater. 40, 163 (1983).
[9] D. G. Rancourt, Hyperfine Interactions 40, 183 (1988).

[10] C. P. Bean, J. D. Livingston, J. Appl. Phys. 30 (Suppl.), 120S (1959).

[11] S. Mørup, J. A. Dumesic, and H. Topsøe, Applications of Mössbauer Spectroscopy 2, page 1, R. L. Cohen (1980).

[12] D. G. Rancourt and J. M. Daniels, Phys. Rev. B 29, 2410 (1984).

[13] F. van der Woude and A. J. Dekker, phys. stat. sol. 9, 775 (1965).

[14] U. Pegelow, PhD thesis, Universität Münster 1993. 